\title{
ANALISIS KEBIJ AKAN DAN PROGRAM SUBSEKTOR PETERNAKAN KABUPATEN LAMPUNG BARAT
}

\author{
(Analyze of Program and Policy of the Animal Husbandry Subsector \\ in West Lampung Regency) \\ Hotmuda Simarmata ${ }^{1}$, Hardinsyah ${ }^{2}$, dan Diah K. Pranadji ${ }^{3}$ \\ ${ }^{1}$ Program Studi Manaj emen Ketahahan Pangan (MKP), Sekolah Pascasarjana, IPB. \\ 2 Departemen Gizi Masyarakat, Fakultas Ekologi Manusia (FEMA), IPB \\ Tel: 0251-8628304/ 8621258; Fax: 0251-8625846/ 8622276 \\ ${ }^{3}$ Departemen IImu Keluarga dan Konsumen, Fakultas Ekologi Manusia (FEMA), IPB \\ Tel: 0251-8628303/ 8627432; Fax: 0251-8625846/ 8622276
}

\begin{abstract}
ABST RACT
This study aims to analyze the policy, program, activity and budgetting of husbandry subsector in West Lampung Regency. The study was conducted retrospectively, studying documents of policy 2003-2007 in Husbandry and Animal Health Agency of West Lampung and interviewing respondents of the officials involved in the drafting of the program, decision makers, and groups of farmers from November to December 2008. Data that were required in this research, consist of primary and secondary data and was analyzed by descriptive analysis, content analysis and SWOT analysis. The results of this research showed that the formulation of policy and program had been in line with the regulation, but there were some constraints in implementing the policy and program in form of activities due to the limited budget. Budgeting allocation portion for the development food resources from husbandry for 4 years was higher than supporting activities, except in the fifth year. Implementation of husbandry sub-sector, especially cattle breeding was enthusiastically welcomed by the community indicated by their high motivation and initiatives. The environment has changed from the previous period so that the future concept will focus on the breeder empowerment and capital access and strategy by intensifying animal breeding culture, building husbandry centers and partnership with private sectors.
\end{abstract}

Keywords: policy, program, strategy, environmental strategy, implementation

\section{PENDAHULUAN}

Berdasarkan Undang-undang nomor 6 tahun 1991, tentang pembentukan kabupaten Lampung Barat, urusan-urusan di bidang peternakan adalah sebagai salah satu kewenangan pangkal dalam rangka penyelenggaraan Pemerintah Daerah Kabupaten Lampung Barat, hal tersebut sudah pasti memberikan kesempatan lebih besar untuk menggerakkan pembangunan subsektor peternakan, yakni tersedianya anggaran dalam APBD Kabupaten Lampung Barat setiap tahunnya.

Pembangunan pada subsektor peternakan berperanan meningkatkan kualitas sumber daya manusia secara berkelanjutan melalui perbaikan gizi, mewujudkan keluarga mandiri gizi, peningkatan pendapatan serta kesejahteraan masyarakat peternak, kesempatan kerja, pelestarian lingkungan hidup dan peningkatan devisa Negara (Direktorat Jenderal Bina Produksi Peternakan, 2003).
Masalah pada subsektor peternakan di Kabupaten Lampung Barat saat ini: pola pemeliharaan (95\%) masih bersifat ekstensif tradisional dan (5\%) semi intensif. Pertambahan populasi berbagai jenis ternak masih sangat rendah berkisar $(0.41 \%-0.75 \%)$, sedangkan penurunan terjadi pada ternak ayam buras sebesar $39.24 \%$ ketersediaan pangan hewani asal ternak (daging) (73.28\%) berasal dari luar dan (26.72\%) produksi sendiri; telur $(70 \%$ berasal dari luar dan (30\%) produksi sendiri. Hal tersebut diduga ada hubungannya dengan kebijakan, program dan kegiatan yang dirumuskan ditetapkan dan diimplementasikan dalam kegiatan pembangunan subsektor peternakan di Lampung Barat, periode $2003-2007$.

Bertitik tolak pada alasan-alasan tersebut, penulis melihat perlu diadakan penelitian dalam rangka untuk menganalisis kebijakan, program, kegiatan serta anggaran pada subsektor peternakan di Kabupaten Lampung Barat. 
Tujuan umum penelitian ini menganalisis kebijakan program dan kegiatan subsektor peternakan periode 2003 - 2007 serta lingkungan strategis yang dapat mempengaruhi perumusan strategi dan kebijakan subsektor peternakan di Kabupaten Lampung Barat masa yang akan datang. Tujuan khusus penelitian ini (1) menganalisis kebijakan, program dan kegiatan peternakan selama lima tahun anggaran periode 2003-2007 (2) menganalisis alokasi anggaran (porsi anggaran) pada subsektor peternakan terhadap pengembangan sumber daya pangan (SDP) peternakan. (3) mengidentifikasi dan menganalisis lingkungan strategis subsektor peternakan di Kabupaten Lampung Barat. (4) merumuskan strategi dan kebijakan subsektor peternakan di kabupaten Lampung Barat untuk masa yang akan datang.

Kegunaan penelitian ini adalah sebagai informasi tentang kebijakan, program, kegiatan, jumlah alokasi anggaran pengembangan subsektor peternakan dalam kurun waktu 2003 - 2007 serta merekomendasikan konsep strategi dan kebijakan pembangunan subsektor peternakan untuk masa mendatang kepada berbagai pihak (stakeholder), khususnya Pemerintah Kabupaten Lampung Barat dalam kapasitasnya sebagai pengambil kebijakan (decision maker).

\section{METODE PENELITIAN}

\section{Desain dan Tempat Penelitian}

Penelitian ini menggunakan desain cross sectional study, dilakukan secara retrospektif, berupa review terhadap dokumen kebijakan dan perencanaan (2003 - 2007), di Dinas Peternakan dan Kesehatan Hewan Kabupaten Lampung Barat dan wawancara kepada sejumlah responden yang ditentukan secara sengaja (purposive), yakni beberapa Pejabat di Dinas Peternakan dan Kesehatan Hewan, Bappeda, komisi B DPRD Kabupaten Lampung Barat pada tataran kebijakan dan program serta kepada kelompok tani ternak pada tataran implementasi kegiatan.

\section{Jenis dan Cara Pengumpulan Data}

J enis data yang dibutuhkan dalam penelitian ini adalah data primer dan data sekunder baik berupa data kuantitatif maupun kualitatif. Data primer diperoleh melalui wawancara (Interview) menggunakan daftar pertanyaan (kueisioner) kepada anggota kelompok tani penerima paket ternak sapi dan kambing sebanyak 10 kelompok dalam kurun waktu
2003 - 2007 dan kepada para pejabat tataran program dan tataran kebijakan. Data primer yang dikumpulkan adalah sebagai berikut: pada tingkat petani peternak berupa (1) Manfaat yang diperoleh selama memelihara paket ternak pemerintah; (2) Permasalahan yang dialami selama memelihara paket ternak pemerintah; (3) Upaya-upaya yang dilakukan untuk mengatasi permasalahan tersebut; (4) Perkembangan aktifitas kelompok dan ternak yang dipelihara, pada tataran pengambil kebijakan dan program adalah berupa: (1) Prosedur perumusan kebijakan dan program; (2) Kendalakendala yang ada dalam perumusan kebijakan dan program; (3) Faktor-faktor untuk mendukung jumlah alokasi anggaran. Data sekunder diperoleh dengan cara studi dokumentasi terhadap dokumen kebijakan subsektor Peternakan 2003 - 2007. Data sekunder tersebut berupa: (1) Data alokasi anggaran (budgeting) sub sektor peternakan 2003 - 2007. (2) Data dokumen kebijakan peternakan kurun waktu 2003 2007. (3) Data lingkungan strategis untuk perumusan kebijakan dan strategi subsektor peternakan di masa mendatang.

\section{Pengolahan dan Analisis Data}

Pengolahan data dilakukan secara sederhana yaitu tabulasi dan persentasi, data yang dikumpulkan kemudian dianalisis secara deskriptif, analisis SWOT (Strength-WeaknesOportunity-Threaths).

\section{HASIL DAN PEMBAHASAN}

\section{Gambaran Umum Lampung Barat}

Luas wilayah Kabupaten Lampung Barat 495040 ha atau $4950.40 \mathrm{~km}^{2}$ meliputi $17 \mathrm{ke}-$ camatan. Jumlah penduduk sebanyak 410732 jiwa, dengan mata pencahariannya paling dominan pada sektor pertanian $(79.88 \%$ ) (tanaman pangan dan hortikultura, peternakan, perkebunan, perikanan dan kelautan), sektor perdagangan, restoran dan hotel $(6.70 \%)$, sektor jasa (6.83\%), industri pengolahan (1.15\%) dan lainnya (5.44\%). Subsektor peternakan dapat digambarkan sebagai berikut: populasi ternak ayam kampung 367483 ekor, itik 54115 ekor, kambing 71698 ekor, domba 7742 ekor, kerbau 2238 ekor dan sapi 15284 ekor.

\section{Kebijakan dan Program}

Perumusan kebijakan dan program subsektor peternakan sudah dilakukan sesuai dengan prosedur dan mekanisme yang berlaku serta didasarkan pada peraturan perundang- 
undangan yang berlaku. Kendala-kendala yang dialami dalam perumusan kebijakan dan program adalah data kurang tersedia menurut (64.28\%) responden dan kurangnya sumber daya manusia berkualitas menurut (35.72\%) responden.

Berdasarkan surat Keputusan Bupati Lampung Barat nomor: B/ 223/ Kpts/ III. 01/ 2004 tentang Perencanaan Stratejik (Renstra) Dinas / Lembaga teknis/Instansi Pemerintah Tahun 2003 - 2007, kebijakan dan program subsektor peternakan adalah sebagai berikut: Jumlah kebijakan sebanyak 14 kebijakan yang dikelompokkan dalam bidang-bidang, antara lain: perencanaan 1 buah, produksi 5 buah, bidang kesehatan hewan dan kesehatan masyarakat veteriner 4 buah serta bidang bina usaha 4 buah. Jumlah program adalah sebanyak 45 program, yakni bidang perencanaan 6 buah, bidang produksi 12 buah, bidang keswan dan kesmavet 14 buah, bina usaha 13 buah.

\section{Kegiatan dan Anggaran 2003-2007}

\section{Realisasi kegiatan dan anggaran}

Gambaran realisasi kegiatan subsektor peternakan 2003 - 2007 menurut kelompok bidang tugas adalah sebagai berikut: J umlah kegiatan yang dominan setiap tahun, adalah bidang produksi, bidang kesehatan hewan dan kesehatan masyarakat veteriner, sedangkan pada bidang bina usaha dan perencanaan relatif lebih sedikit, hal ini disebabkan kurangnya perhatian dan dukungan terhadap kedua bidang tersebut dan pola pikir yang hanya berorientasi pada sesuatu yang bersifat fisik, sebaiknya hal ini harus diminimalisir agar pelaksanaan pembangunan subsektor peternakan lebih proporsional.

Alokasi anggaran pengembangan sumber daya pangan peternakan selama 2003 - 2007 adalah sebagai berikut ini:

1. Porsi alokasi anggaran untuk kegiatan pengembangan sumber daya pangan peternakan selama 5 tahun (2003 - 2007) lebih besar bila dibandingkan dengan porsi kegiatan pendukung kecuali tahun anggaran 2007, alokasi anggaran kegiatan pendukung lebih besar daripada alokasi anggaran kegiatan utama yaitu Rp 539939000 (54.66\%) dan kegiatan utama sebesar Rp447 923000 (45.34\%).

2. Total anggaran pembangunan pada subsektor peternakan selama 2003 - 2007, setiap tahun mengalami kenaikan kecuali tahun 2005 mengalami penurunan sebesar Rp 44879225 (8.25\%) dari tahun anggaran 2004.
Dampak Implementasi Kegiatan Bagi Kelompok Tani Ternak.

\section{Motivasi kelompok tani ternak}

Salah satu manfaat dari adanya kegiatan pengembangan ternak oleh pemerintah adalah memberikan motivasi kepada masyarakat berupa:

a. dorongan untuk mengikuti program dan memelihara ternak kambing dan sapi sebagian besar atas inisiatif sendiri yakni kambing $(68 \%)$, sapi (56\%): mengikuti tetangga masing-masing ternak kambing (32\%), sapi (16\%) dan anjuran dinas hanya ternak sapi sebesar (28\%).

b. Sistem program pengembangan ternak pemerintah mayoritas disukai adalah Bantuan Pinjaman Langsung Masyarakat (BPLM), ternak kambing $(76 \%)$, ternak sapi $(92 \%)$, sedangkan sistem gaduhan relatif lebih sedikit yaitu ternak kambing (24\%) dan ternak sapi $(8 \%)$.

c. Kelebihan sistem gaduhan menurut responden adalah cepat lunas ternak (8\%), ternak sapi sebanyak (60\%); memperoleh modal ternak kambing $(16 \%)$, ternak sapi hanya (84\%). Kelemahannya menurut responden adalah administrasinya rumit ternak kambing (48\%), ternak sapi (8\%); sistem pelaporan rumit khusus ternak kambing (28\%), ternak sapi tidak masalah.

d. J umlah ternak kambing yang diperoleh kebanyakan (1 - 3) ekor (80\%) dan (4 - 5) ekor $(20 \%)$ responden, sedangkan kelompok ternak sapi dominan mendapat sebanyak (1 - 3) ekor. Lamanya beternak para anggota kelompok mayoritas masih pemula (1 - 3) tahun untuk kelompok kambing sebanyak (60\%) dan kelompok ternak sapi $(68 \%)$, sedangkan madya dan lanjut adalah kelompok kambing (28\%) dan (12\%), sedangkan kelompok sapi masing-masing (8\%) responden.

\section{Manfaat diperoleh kelompok}

Manfaat yang diperoleh anggota kelompok tani ternak kambing dan sapi dari program pengembangan ternak pemerintah adalah: sebagai penghasilan tambahan, mendapat modal, memperoleh pupuk kandang, sebagai tabungan. Manfaat lainnya seperti mendapatkan pembinaan pemerintah sangat dirasakan oleh kelompok ternak sapi dan kelompok ternak kambing (88\%) responden, belajar organisasi pada kelompok kambing sama dengan kelompok sapi yaitu (80\%) responden dan sebagai peluang usaha lebih besar pada kelompok sapi (88\%) responden dibanding kelompok kambing hanya $(76 \%$ ). 


\section{Permasalahan Dialami Kelompok}

Permasalahan yang dialami anggota kelompok ternak dalam mengikuti program pengembangan ternak Pemerintah di Kabupaten Lampung Barat adalah sebagai berikut: masalah penyakit ternak menduduki urutan pertama yakni kelompok ternak kambing sebanyak (68\%) dan kelompok ternak sapi sebanyak $(60 \%)$, diikuti masalah pemeliharaan kelompok kambing (24\%) dan sapi (28\%) serta masalah paling kecil adalah pengembalian yaitu kelompok kambing (8\%) dan sapi (12\%), hasil wawancara kelompok tani ternak tahun 2008.

Upaya-upaya yang dilakukan untuk mengatasi masalah tersebut adalah melakukan pengobatan penyakit ternak dengan cara meminta bantuan petugas peternakan dilakukan responden peternak kambing (68\%), peternak sapi (80\%); dan sisanya dilakukan sendiri oleh peternak kambing dan peternak sapi.

\section{Analisis SWOT}

\section{Identifikasi Lingkungan Strategis} berikut:

Kekuatan (strengths) adalah sebagai

1. Adanya peraturan perundang-undangan yang mendukung Dinas Peternakan dan Kesehatan Hewan

2. Tersedianya tenaga aparatur di bidang peternakan

3. Tersedianya teknologi yang mendukung pengembangan peternakan

4. Agroklimat dan pakan ternak yang mendukung.

5. Adanya kebijakan untuk meningkatkan produksi peternakan

6. Adanya kebijakan penanggulangan penyakit hewan menular

7. Adanya dukungan dana dari pemerintah

8. Adanya Unit Pelaksana Teknis (UPT) Dinas Peternakan dan Kesehatan Hewan

9. Adanya kelompok tani ternak sudah terbina.

berikut:

Kelemahan (Weaknesses) adalah sebagai

1. Kuantitas dan kualitas Sumber Daya Manusia peternakan masih kurang

2. Check point dan RPH kurang memadai

3. Kurangnya data dan informasi peternakan

4. Budi daya ternak masih bersifat extensif tradisional

5. Produktifitas ternak rendah, belum dapat memenuhi kebutuhan lokal

6. Angka kematian dan kesakitan ternak masih tinggi

7. Pengetahuan petani masih rendah.

8. Prasarana dan sarana masih minim
9. Pengawasan mutu produk masih kurang. berikut:

Peluang (opportunities) adalah sebagai

1. Adanya lembaga-lembaga: Pendidikan Litbangnak, Diklat, Balai dan UPTD IB

2. Permintaan produk Peternakan tinggi

3. Tingginya minat masyarakat untuk memelihara ternak

4. Tumbuhnya usaha jual beli ternak di masyarakat

5. Usaha sapronak berpeluang untuk berkembang.

Ancaman/Tantangan (threaths) adalah sebagai berikut:

1. Upaya masuknya produk peternakan dari luar ke Lampung Barat

2. Jarak tempuh pelayanan kesehatan hewan sangat jauh

3. Adanya wabah penyakit menular

4. Investasi pada usaha peternakan masih rendah.

5. Pemotongan ternak betina produktif.

Matrik Evaluasi Faktor-faktor Internal dan Eksternal

Pemetaan posisi subsektor peternakan berada pada koordinat sebagai berikut: Posisi pada sumbu $X=$ kekuatan - kelemahan $=3.49$ $3.12=0.37$. Posisi pada sumbu $Y=$ peluang ancaman $=3.63-3.43=0.20$ kemudian koordinat ini digambarkan pada diagram analisis SWOT, diperoleh posisi pada kuadran I, artinya menggunakan strategi Agresif, yakni: menggunakan kekuatan untuk memanfaatkan peluang.

\section{Strategi Pembangunan Peternakan}

Strategi berdasarkan hasil analisis SWOT menurut prioritas adalah sebagai berikut:

1. Intensifikasi budi daya berbagai jenis ternak.

2. Peningkatan pelayanan kesehatan hewan untuk penanggulangan penyakit ternak.

3. Optimalisasi penggunaan teknologi tepat guna di bidang peternakan.

4. Peningkatan SDM peternakan melalui pelatihan-pelatihan dan magang.

5. Pemberdayaan petani peternak.

6. Pengalokasian anggaran untuk diklat-diklat dan penelitian, budidaya dan pembangunan pasar ternak.

7. Penetapan kawasan dan sentra-sentra usaha peternakan.

8. Penyuluhan dan pembinaan bidang peternakan.

9. Regulasi budi daya, perdagangan dan investasi bidang peternakan.

10. Pengembangan agribisnis peternakan. 
11. Membangun kerjasama di bidang peternakan dengan lembaga-lembaga terkait dan perusahaan-perusahaan peternakan.

12. Mendorong tumbuhnya usaha sarana produksi peternakan.

13. Mempermudah perizinan usaha peternakan.

\section{Kebijakan Masa mendatang}

Sesuai dengan strategi pembangunan peternakan hasil analisis SWOT, dirumuskan konsep kebijakan pembangunan subsektor peternakan dan kesehatan hewan untuk masa mendatang difokuskan pada aspek-aspek sebagai berikut:

1. Peningkatan usaha budi daya pada subsektor peternakan.

2. Peningkatan status kesehatan hewan.

3. Peningkatan aplikasi teknologi peternakan.

4. Peningkatan SDM peternakan (aparatur dan petani peternak).

5. Pemberdayaan petani peternak.

6. Peningkatan alokasi anggaran.

7. Penetapan kawasan dan sentra-sentra usaha peternakan.

8. Penyuluhan dan pembinaan peternakan.

9. Regulasi pada subsektor peternakan.

10. Pengembangan agribisnis peternakan.

11. Peningkatan kerjasama/kemitraan di bidang peternakan.

12. Mendorong tumbuh berkembangnya usaha peternakan.

13. Perizinan di bidang peternakan.

Dalam rangka untuk mengoperasionalkan strategi dan kebijakan subsektor peternakan tersebut harus dijabarkan ke dalam kegiatan tahunan.

\section{KESIMPULAN}

Kebijakan dan program sub sektor peternakan 2003 - 2007 belum sepenuhnya dapat diimplementasikan dalam kegiatan operasional pembangunan subsektor peternakan. Porsi alokasi anggaran subsektor peternakan terhadap pengembangan sumber daya pangan sudah lebih dominan dan lebih besar jumlahnya apabila dibandingkan dengan kegiatan pendukung, namun kenaikan anggaran tidak berbanding lurus dengan porsi alokasi anggaran untuk pengembangan sumber daya pangan peternakan.

Berdasarkan kondisi 2008, lingkungan strategis pembangunan subsektor peternakan tahun 2003 - 2007 sudah banyak mengalami perubahan antara lain: Struktur organisasi, sehingga strategi dan kebijakan untuk pembangunan subsektor peternakan masa mendatang juga mengalami penyempurnaan dari periode sebelumnya.

Konsep kebijakan pembangunan subsektor peternakan Kabupaten Lampung Barat di masa yang akan datang difokuskan kepada intensifikasi budidaya, peningkatan SDM, pemberdayaan peternak, peningkatan alokasi anggaran, regulasi peternakan, pengembangan agribisnis, kemitraan dan mendorong tumbuh berkembangnya usaha peternakan.

Strategi pembangunan subsektor peternakan Kabupaten Lampung Barat di masa mendatang diprioritaskan kepada intensifikasi, pelayanan kesehatan hewan, aplikasi teknologi tepat guna, sumberdaya manusia, sentra-sentra peternakan, penyuluhan dan pembinaan, agribisnis, regulasi, kemitraan dan perizinan.

\section{DAFTAR PUSTAKA}

[Ditjennak] Direktorat Jenderal Peternakan. 2003. Pedoman Pelaksanaan Tahun 2003 sebagai Tahun Kebangkitan Peternakan dan Kesehatan Hewan Indonesia. Direktorat J enderal Peternakan, Departemen Pertanian, Jakarta.

Keputusan Bupati Lampung Barat Nomor B/ 223 / KPTS/ III. 01/ 2004 tentang Rencana Strategik Dinas/ Lembaga Teknis/ Instansi Pemerintah Kabupaten Lampung Barat, Renstra 2003-2007. 